\title{
Molecularly Imprinted Electrochemical Sensor for Detection of Prednisolone in Human Plasma as a Doping Agent in Sports
}

\author{
Youliang Li, Yujun Xiong* \\ School of Physical Education, East China University of Technology, Nanchang, 330013, China \\ "E-mail: yujun_xiong2021@163.com
}

Received: 11 June 2021/ Accepted: 5 August 2021 / Published: 10 September 2021

\begin{abstract}
This work was carried out on the synthesis of poly(4-vinylpyridine)- molecularly imprinted polymer on graphene oxide (4-VP/MIP/GO) as an electrochemical sensor for detection of prednisolone as a doping agent in sports. The GO was prepared using the modified Hummers method and electrodeposited on a glassy carbon electrode (GCE). The GO/GCE was modified by MIP which was prepared from tetrabutylammonium perchlorate and acetonitrile, and then 4-VP was electrodeposited on MIP/GO/GCE. Results of morphological analysis of modified electrodes using FESEM revealed GO was overlapping of flake nanosheets on the surface with cracks and fractures. The surface morphology of 4VP/MIP/GO/GCE also showed a highly porous structure due to created cavities from the agglomeration of 4-VP and MIP molecules on corrugated edges of GO nanosheets. Results of electrochemical studies using DPV technique showed good stability, high selectivity, acceptable linear range $(1 \mu \mathrm{M}$ to $120 \mu \mathrm{M})$, highest selectivity $(0.7397 \mu \mathrm{A} / \mu \mathrm{M})$ and lowest detection limit $(0.004 \mu \mathrm{M})$ in comparison with the other synergetic effect of GO nanosheets and 4-VP and MIP molecules. The validity and precision of 4VP/MIP/GO/GCE to the determination of prednisolone were evaluated in pharmaceutical samples and human biological fluids and results exhibited acceptable recovery values (96 to $99.38 \%$ ) and RSD values (2.53 to $3.89 \%$ ). Therefore, 4-VP/MIP/GO/GCE can be used as an accurate and reliable sensor for determination of prednisolone as a doping agent in sports.
\end{abstract}

Keywords: Graphene oxide; Molecularly imprinted polymers; Prednisolone; Steroidabuse; Clinical Samples; Differential pulse voltammetry

\section{$\underline{\text { FULL TEXT }}$}

(C) 2021 The Authors. Published by ESG (www.electrochemsci.org). This article is an open access article distributed under the terms and conditions of the Creative Commons Attribution license (http://creativecommons.org/licenses/by/4.0/). 